\title{
Deep inside of gastric signet-ring cell carcinoma
}

\author{
L. RONCATI ${ }^{1, *}$, A. MANENTI², G. BARBOLINI ${ }^{1}$, A. MAIORANA ${ }^{1}$ \\ ${ }^{1}$ Department of Diagnostic and Clinical Medicine and of Public Health, Division of Pathology, University of Modena and Reggio Emilia, Modena \\ (MO), Italy; ${ }^{2}$ Department of Medical and Surgical Sciences, Division of Surgery, University of Modena and Reggio Emilia, Modena (MO), Italy
}

${ }^{*}$ Correspondence: emailmedical@gmail.com

Received April 5, 2017 / Accepted September 27, 2017

\begin{abstract}
The histology of signet-ring cell carcinoma (SRC) of the stomach has been revisited with the support of current immunohistochemical techniques in order to explain particular features of this tumor; its great capacity of local diffusion and lymph node metastasis, also through a neo-lymphoangiogenesis. An observational retrospective study on 50 cases of SRC in stage II and III has been performed with the addition of histochemical (Alcian Blue, DDD-Fast Blue B, Mercury Orange) and immunohistochemical (cytocheratin, CD3, CD4, CD8, CD10, CD56, CD68, perforin, granzyme B, podoplanin, collagen type IV) investigations for each case. The signet ring cells, typical for this tumor, show abundant content of electro-negative sialomucins and demonstrate a great capacity of diffusion through the gastric wall. They evoke production and deposition of collagen type IV in the sub-mucosa layer through the local action of fibroblasts. The immunological response to this tumor in the gastric wall and in the metastatic lymph nodes is represented by an increase of B and T-helper lymphocytes, but not of T-killers or natural killers. The neoplastic cells are curiously able to avoid these newly formed 'lymph nodules'. An extended neo-lymphangiogenesis has been observed around the primary tumor and in metastatic lymph nodes. A careful immunohistochemical characterization has allowed a better knowledge of SRC, regarding especially the peculiar behavior of local diffusion of its cells, the associated neo-lymph angiogenesis, and poor immunological reaction.
\end{abstract}

Key words: undifferentiated gastric carcinoma, signet-ring cell carcinoma, lymphangiogenesis, tumor-infiltrating lymphocytes, cancer, histology

Stomach cancers are overwhelmingly composed of adenocarcinomas (90\%), followed by lymphomas (5\%), carcinoids and stromal tumors [1]. Histologically, according to the Lauren's classification there are two major types of gastric adenocarcinomas: intestinal type or diffuse type. Intestinal type adenocarcinoma tends to form glandular structures with multiple lumens and reduced stroma with a backto-back' appearance. Often, it associates with intestinal metaplasia in neighboring mucosa. Depending on glandular architecture, cellular pleomorphism and muco-secretion, it can present three degrees of differentiation: well differentiated (G1), moderate differentiated (G2) and poorly differentiated/undifferentiated (G3) [1]. Diffuse type adenocarcinoma (linitis plastica, leather-bottle stomach) tumor cells are discohesive and secrete mucus, which can be delivered into the interstitium and produce large pools, or can remain inside the tumor cell, pushing the nucleus to the periphery in a 'signet-ring' fashion. By definition, diffuse type adenocarcinoma is poorly differentiated/undifferentiated [1]. The great majority of gastric adenocarcinomas develops histologically differentiated tumors and a significant proportion of these progress until they become undifferentiated. However, a subset of gastric adenocarcinomas develops as undifferentiated carcinomas, including signet-ring cell carcinoma (SRC) [1]. Our attention has been precisely focused on SRC for its particular histological features and clinical behavior. Today, the immunohistochemical techniques allow to better understand local and distant diffusion. Cancer is in fact characterized by some major hallmarks: sustaining proliferative signaling, evading growth suppressors, activating invasion and metastasis, enabling replicative immortality, inducing angiogenesis and resisting cell death [2]. From the beginning of XXI century, several evidences support the importance of immunity against cancer and, therefore, the ability to escape immune-mediated destruction was introduced as a further hallmark of cancer [3]. The most commonly used system for classifying the tumor extent and spread is TNM (Tumor Node Metastasis). However, it is well-known that the system 
fails to consider the effects of host immune response against cancer cells and that clinical outcome can significantly vary among patients within the same TNM stage [4]. To overcome this limit, the concept of immunoscore was proposed, which incorporates immunity into tumor classification, improving the prognostic accuracy [5]. It is based on the evaluation and quantification of tumor-infiltrating lymphocytes and in situ immune response [6]. By exploiting specific immunohistochemical antibodies, we have also investigated in SRC all of the main lymphocytic sub-populations, the related most common molecules of cytotoxicity, and the presence of histocytes, fibroblasts and collagen type IV, and correlated them with the above-mentioned cancer hallmarks of lymphangiogenesis and disruptive growth.

\section{Patients and methods}

Retrospectively, we have in-depth evaluated the histology of 50 SRC cases, 25 females and 25 males, aged between 53 and 76 years, diagnosed from 2000 to 2010. All these patients were submitted to a curative subtotal distal gastrectomy with D2-lymphadenectomy and the gastric tumor was confirmed to be SRC in stage II (27 cases) or III (23 cases).
An unfavorable course of the neoplastic disease followed in all cases, with decease within 36 months. From a representative paraffin block of each neoplastic case, new tissue sections were obtained and submitted to histochemistry (Alcian Blue, DDD-Fast Blue B, Mercury Orange) and immunohistochemical characterization. More in detail, after deparaffinization, hydration, endogenous peroxidase blocking and heatinduced antigen retrieval, the tissue sections were incubated for 30 minutes at room temperature with anti-cytokeratin (clone MNF116; Dako, Glostrup, Denmark), anti-CD3 (clone 2GV6; Ventana, Tucson, AZ, USA), anti-CD4 (clone SP35; Ventana), anti-CD8 (clone SP57; Ventana), anti-CD10 (clone SP67; Ventana), anti-CD56 (clone SP35; Ventana), anti-CD68 (clone KP1; Ventana), anti-perforin (clone MRQ-23; Ventana), anti-granzyme B (polyclonal; Ventana), anti-podoplanin (clone D2-40; Ventana), anti-collagen type IV (CIV22; Ventana). Biotinylated secondary antibody was applied and the staining product was detected with avidinbiotin complex against a hematoxylin counterstain. Detection of the staining reaction was achieved by an enzyme conjugated polymer complex adapted for automatic stainers from Roche Ventana Medical Systems, with 3-3' diaminobenzidine tetrahydrochloride as chromogen.
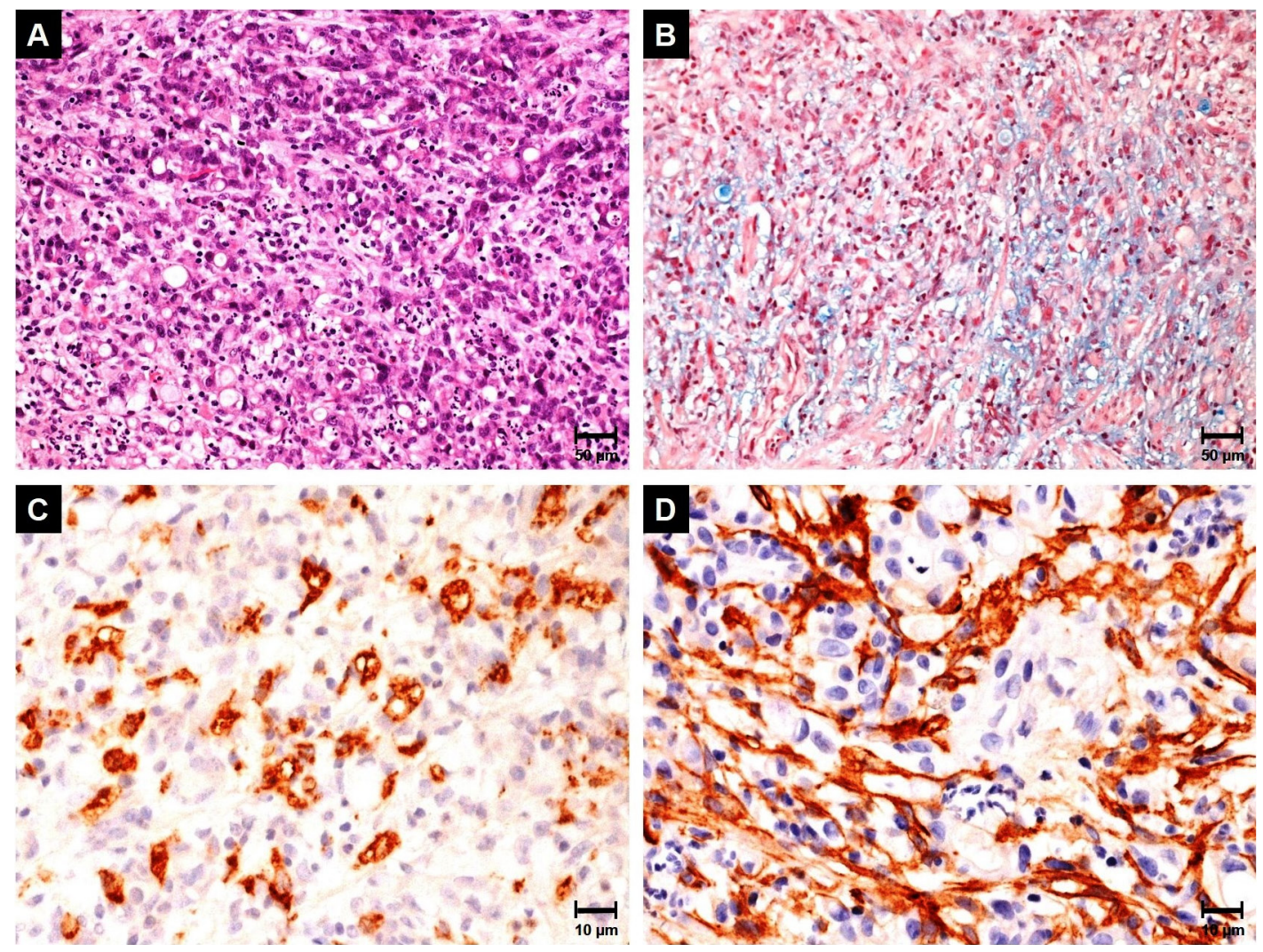

Figure 1. Gastric signet-ring cell carcinoma characterized by the presence of classical signet-ring cells (A, H\&E, 20x): inside and outside of the neoplastic cells, accumulations of blue-stained sialomucins are observable (B, Alcian Blue, $\mathrm{pH} 2.5,20 \times)$. Several histocytes are intermingled with the cancer cells $(\mathrm{C}, \mathrm{CD} 68,50 \mathrm{X})$, and a diffuse deposition of collagen type IV is noticeable (D, collagen type IV, 50x). 


\section{Results}

Inside the core of all primary tumors, only scanty CD68-positive macrophages (Figure 1) without neutrophils was observed. The apoptosis-derived fragments of neutrophil cells, usually present in other more differentiated carcinomas were absent. Around the primitive tumors, a neo-lymphangiogenesis was observed, represented by fine lymphatic podoplanin-positive capillaries, provided with a single layer of endothelial cells devoid of valves or other structures. Deposits of neoplastic cells were found inside in all cases. Interesting was the behavior of the signet-ring cells, typical constituents of this cancer. The abundant content of sialomucins present inside their cytoplasm was demonstrated by Alcian Blue staining (Figure 1). The accumulation of glycoconjugates rich in sialyl groups was further confirmed by both DDD-Fast Blue B and Mercury Orange staining methods for thiols. These cells did not aggregate in glandular-like structures, neither in the primary tumor, nor in the metastatic lymph nodes. True budding of compact structures was therefore absent. On the contrary, in all the examined cases we observed a migration of these elements through the entire gastric wall in a procession-like fashion, coordinated to get away from the 'lymph nodules' in order to escape them. This surprising attitude was well highlighted by immunohistochemistry for cytokeratin (Figure 2). These nodules, containing different types of lymphocytes, were mainly situated in the gastric submucosa (Figure 2), but also in the muscularis and sub-serosa layer, where their number increased passing from stage II to stage III. They did not further evolve toward true lymph nodes, but originated active germinative follicles. The immunohistochemical characterization of the cell population demonstrated an increase of CD20-positive B lymphocytes and CD4-positive T-helper, but not of CD8-positive T-killer or CD56-positive natural $(\mathrm{N})$ killer lymphocytes in all cases (Figure 2). Moreover, we noted the absence of perforin and granzyme $\mathrm{B}$, molecules with a notorious cytotoxic activity. Besides, in


Figure 2. Numerous 'lymph nodules' in the submucosa of a stomach involved in signet-ring cell carcinoma (A, H\&E, 5×); neoplastic cells, brownstained by anti-cytokeratin, escape the 'lymph nodules' (B, cytokeratin, $5 \times)$. They consist of B lymphocytes (C, CD20, 5x), T-helper lymphocytes (D, $\mathrm{CD} 4,5 \times)$ and only scant $\mathrm{T}$-killer lymphocytes $(\mathrm{E}, \mathrm{CD} 8,5 \times)$. 
the gastric sub-mucosa, we observed an increased number of CD10-positive fibroblasts, accompanied by an abundant deposition of collagen type IV in 100\% of cases (Figure 1). The metastatic lymph nodes appeared located not following a continuous array, but scattered in the whole tributary zone. Inside of them we noticed the same cells, just ascertained in the 'lymphatic nodules'. A neo-lymphangiogenesis, equivalent to that of the primary tumor was associated in all cases (Figure 3). The lymph nodes not involved in metastasis showed a normal compartmentalization with a standard lymphocytic distribution in absence of neo-lymphangiogenesis.

\section{Discussion}

The abundant content of sialomucins inside the cytoplasm of the tumor cells gives them the typical signet-ring appearance and determines a negative electric charge on their surface. This opposes their contiguous standing and generation of budding and gland-like structures [4]. A cross-talking develops between SRC and the tissue immune-competent cells, and involves the 'lymphatic nodules', which show germinative centers, increase in number, and become present along the entire gastric wall, also where they are usually absent. Their immunological activation is expressed by newly produced B-lymphocytes and T-helper, but not T-killer or N-killer lymphocytes, which could express a cytotoxic action against the neoplastic cells. This correlates well with the absence of corresponding markers of cytotoxicity, such as perforin and granzyme B. We are prone to believe that this immunosuppressive activity is performed by SRC cells through the selective release of cytokines, which by a paracrine action inhibit the recruitment of T-killer or N-killer lymphocytes, potentially active against the neoplastic elements [7]. This equally takes place in the lymphatic structures of the gastric wall and of the metastatic lymph nodes. Similarly, the numerous fibroblasts present in the sub-mucosa generate collagen IV, an extracellular component that does not seem to influence per se the diffusion of the neoplastic cells. However, the same
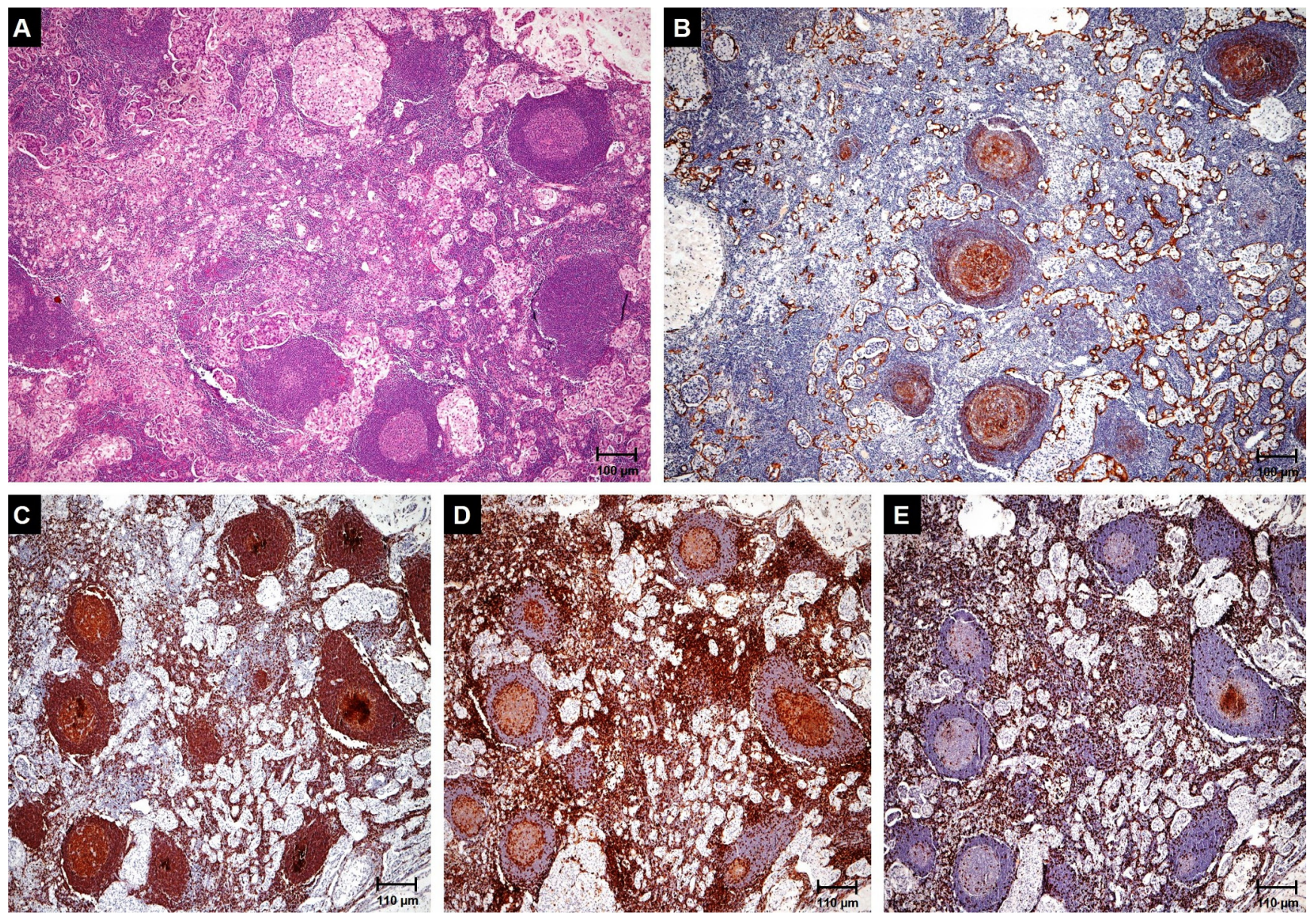

Figure 3. Nodal metastasis from gastric signet-ring cell carcinoma (A, H\&E, $5 \times)$; the neoplastic nests evoke a conspicuous neo-lymphangiogenesis, invading the newly formed lymphatic capillaries $(B$, podoplanin, $5 \times)$. The residual lymph node shows a prevalence of $B(C, C D 20,5 \times)$ and T-helper $(D$, CD4, 5x) lymphocytes, with only scant T-killer lymphocytes (E, CD8, 5×). 
activated fibroblasts are considered as agents potentially favoring the growth and diffusion of the neoplastic cells [8-11]. The presence of macrophages inside the tumor and in the metastatic lymph nodes testifies their role in promoting the tumor growth and diffusion through a neo-lymphoangiogenesis stimulated by the release of humoral vascular growth factors. The absence of any other type of inflammatory circulating cells in the primary tumor or in the metastatic lymph nodes supports this interpretation, suggesting a particular nature and role of these macrophages [12-15]. The evident neo-lymphangiogenesis that accompanies the development of SRC, correlates with the great invasiveness of this cancer. It can be favored by various humoral factors released by different cellular components, directly or indirectly correlated with the tumor growth. Here, paracrine action can be considered [16-21]. The methodology of our study is rather not complete. It would be interesting to research the same histological aspects in the hepatic or pulmonary metastases from SRC, but the rapid and unfavorable course of the neoplastic disease made this impossible. We acknowledge that our results could be better and more appropriately interpreted, if disposing of equivalent complete bio-humoral correlations. This could not be performed by our observational retrospective methodology.

Our observations confirm SRC as a highly malignant tumor with a great local invasiveness and power of metastasizing. It is not accompanied by an effective immunological response. The contemporary process of neo-lymphoangiogenesis represents a direct consequence [22-25]. We hope that in a near future, the classification and staging of each gastric tumor case will include its immunological characterization, a complete study of its lymphatic apparatus, and of the immune response [26-33]. Our research represents a first approach to this problem, even if limited to a single particular gastric cancer.

Acknowledgments: This work was supported by the Italian Research Program of Emilia Romagna Region for the University of Modena and Reggio Emilia (CUP E35E09000880002).

\section{References}

[1] AJANI JA, IN H, SANO T, GASPAR LE, ERASMUS JJ et al. 17. Stomach, p. 212. In: MB Amin, SB Edge, FL Greene, DR Byrd, RK Brookland (Eds.), AJCC cancer staging manual, 8th Edition. Chicago, Springer-Verlag, 2017, pp. 1024. ISBN 9783319406176

[2] HANAHAN D, WEINBERG RA. The hallmarks of cancer. Cell 2000; 100: 57-70.

[3] HANAHAN D, WEINBERG RA. Hallmarks of cancer: the next generation. Cell 2011; 144: 646-674. https://doi. org/10.1016/j.cell.2011.02.013

[4] RONCATI L, BARBOLINI G, GATTI AM, PUSIOL T5, PISCIOLI F et al. The uncontrolled sialylation is related to chemoresistant metastatic breast cancer. Pathol Oncol Res 2016; 22: 869-873. https://doi.org/10.1007/s12253-016-0057-6
[5] GALON J, PAGES F, MARINCOLA FM, ANGELL HK, THURIN $\mathrm{M}$ et al. Cancer classification using the Immunoscore: a worldwide task force. J Transl Med 2012; 10: 205. https://doi.org/10.1186/1479-5876-10-205

[6] GALON J, MLECNIK B, BINDEA G, ANGELL HK, BERGER A et al. Towards the introduction of the 'Immunoscore' in the classification of malignant tumours. J Pathol 2014; 232: 199-209. https://doi.org/10.1002/path.4287

[7] SAITO H, MIYATANI K, TAKAYA S, KURODA H, MATSUNAGA $\mathrm{T}$ et al. Tumor infiltration pattern into the surrounding tissue has prognostic significance in advanced gastric cancer. Virchows Arch 2015; 467: 519-523. https://doi. org/10.1007/s00428-015-1811-y

[8] OKITA Y, OHIRA M, TANAKA H, TOKUMOTO M, GO $\mathrm{Y}$ et al. Alteration of $\mathrm{CD} 4 \mathrm{~T}$ cell subsets in metastatic lymph nodes of human gastric cancer. Oncol Rep 2015; 34: 639647. https://doi.org/10.3892/or.2015.4064

[9] BHOWMICK NA, NEILSON EG, MOSES HL. Stromal fibroblasts in cancer initiation and progression. Nature 2004; 432: 332-337. https://doi.org/10.1038/nature03096

[10] SUN Q, LIN P, ZHANG J, LI X, YANG L et al. Expression of fibroblast growth factor 10 is correlated with poor prognosis in gastric adenocarcinoma. Tohoku J Exp Med 2015; 236: 311-318. https://doi.org/10.1620/tjem.236.311

[11] BAI YP, SHANG K, CHEN H, DING F, WANG Z et al. FGF-1/-3/FGFR4 signaling in cancer-associated fibroblasts promotes tumor progression in colon cancer through Erk and MMP-7. Cancer Sci 2015; 106: 1278-1287. https://doi. org/10.1111/cas.12745

[12] YASHIRO M, MATSUOKA T. Fibroblast growth factor receptor signaling as therapeutic targets in gastric cancer. World J Gastroenterol 2016; 22: 2415-2423. https://doi. org/10.3748/wjg.v22.i8.2415

[13] RIABOV V, GUDIMA A, WANG N, MICKLEY A, OREKHOV A et al. Role of tumor associated macrophages in tumor angiogenesis and lymphangiogenesis. Front Physiol 2014; 5: 75. https://doi.org/10.3389/fphys.2014.00075

[14] BAER C, SQUADRITO ML, LAOUI D, THOMPSON D1, HANSEN SK et al. Suppression of microRNA activity amplifies IFN- $\gamma$-induced macrophage activation and promotes anti-tumour immunity. Nat Cell Biol 2016; 18: 790-802. https://doi.org/10.1038/ncb3371

[15] KIM KJ, WEN XY, YANG HK KIM WH, KANG GH. Prognostic implication of M2 macrophages are determined by the proportional balance of tumor associated macrophages and tumor infiltrating lymphocytes in microsatellite-unstable gastric carcinoma. PLoS One 2015; 10: e0144192. https://doi. org/10.1371/journal.pone.0144192

[16] TAUCHI Y, TANAKA H, KUMAMOTO K, TOKUMOTO $\mathrm{M}$, SAKIMURA C et al. Tumor-associated macrophages induce capillary morphogenesis of lymphatic endothelial cells derived from human gastric cancer. Cancer Sci 2016; 107: 1101-1109. https://doi.org/10.1111/cas.12977

[17] AL-RAWI MA, MANSEL RE, JIANG WG. Lymphangiogenesis and its role in cancer. Histol Histopathol 2005; 20: 283-298. https://doi.org/10.14670/HH-20.283 
[18] RAN S, MONTGOMERY KE. Macrophage-mediated lymphangiogenesis: the emerging role of macrophages as lymphatic endothelial progenitors. Cancers (Basel) 2012; 4: 618-657. https://doi.org/10.3390/cancers4030618

[19] MIGLIOZZI MT, MUCKA P, BIELENBERG DR. Lymphangiogenesis and metastasis--a closer look at the neuropilin/ semaphorin3 axis. Microvasc Res 2014; 96: 68-76. https:// doi.org/10.1016/j.mvr.2014.07.006

[20] PAK KH, JO A, CHOI HJ, CHOI Y, KIM H et al. The different role of intratumoral and peritumoral lymphangiogenesis in gastric cancer progression and prognosis. BMC Cancer 2015; 15: 498. https://doi.org/10.1186/s12885-015-1501-9

[21] JI RC. Lymph node lymphangiogenesis: a new concept for modulating tumor metastasis and inflammatory process. Histol Histopathol 2009; 24: 377-384. https://doi. org/10.14670/HH-24.377

[22] WATANABE M, TANAKA H, OHIRA M, YOSHII M, SAKURAI K et al. Intranodal lymphangiogenesis precedes development of lymph node metastasis and accelerates progression of gastric cancer. J Gastrointest Surg 2014; 18: 481-490. https://doi.org/10.1007/s11605-013-2407-y

[23] TOKUMOTO MW, TANAKA H, TAUCHI Y, KASASHIMA $\mathrm{H}, \mathrm{KURATA} \mathrm{K}$ et al. Identification of tumour-reactive lymphatic endothelial cells capable of inducing progression of gastric cancer. Br J Cancer 2015; 113: 1046-1054. https://doi. org/10.1038/bjc.2015.282

[24] CHANG Y, NIUW, LIAN PL, WANG XQ, MENG ZX et al. Endocan-expressing microvesseldensityas a prognosticfactor for survival in human gastric cancer. World J Gastroenterol 2016; 22: 5422-5429. https://doi.org/10.3748/wjg.v22.i23.5422

[25] ADAMCZYK LA, GORDON K, KHOLOVA, MEIJER-JORNA LB, TELINIUS N et al. Lymph vessels: the forgotten second circulation in health and disease. Virchows Arch 2016; 469: 3-17. https://doi.org/10.1007/s00428-016-1945-6
[26] RONCATI L, MANENTI A, PISCIOLI F PUSIOL T, BARBOLINI G. The immunoscore as a further indicator in carcinoid tumors. Chest 2017; 151: 1186. https://doi.org/10.1016/j. chest.2016.10.032

[27] RONCATI L, MANENTI A, PISCIOLI F, PUSIOL T, BARBOLINI G. Immunoscoring the lymphocytic infiltration in carcinoid tumours. Histopathology 2017; 70: 1175-1177. https://doi.org/10.1111/his.13168

[28] JAGRIC T, GORENJAK M, GOROPEVSEK A. Could the immune response in the sentinel lymph nodes of gastric cancer patients be the key to tailored surgery? Surgery 2016; 160: 613-622. https://doi.org/10.1016/j.surg.2016.04.008

[29] RONCATI L, BARBOLINI G, PIACENTINI F, PISCIOLI F, PUSIOL T et al. Prognostic factors for breast cancer: an immunomorphological update. Pathol Oncol Res 2016; 22: 449-452. https://doi.org/10.1007/s12253-015-0024-7

[30] RONCATI L, MANENTI A, FARINETTI A, PUSIOL T. The association between tumor-infiltrating lymphocytes (TILs) and metastatic course in neuroendocrine neoplasms. Surgery 2016; 160: 1709. https://doi.org/10.1016/j. surg.2015.12.030

[31] MANENTI A, RONCATI L, SIGHINOLFI P, BARBOLINI $\mathrm{G}$. Absence of immune response as a sign of tissue tolerance in small-cell lung cancer. Gene Cell Tissue 2014; 1: e20330. https://doi.org/10.17795/gct-20330

[32] RONCATI L, MANENTI A, PUSIOL T, PISCIOLI F, BARBOLINI G. The lymphocytic inflammation correlates with metastatic risk in carcinoid tumors. Inflamm Cell Signal 2015; 2: e1049. https://doi.org/10.14800/ics.1049

[33] RONCATI L, MANENTI A, PISCIOLI F, PUSIOL T, BARBOLINI G. Spontaneous regression of bronchial carcinoid is linked to a 'brisk' tumor lymphocytic infiltrate. J Bronchology Interv Pulmonol 2017; 24: e26-27. https://doi. org/10.1097/LBR.0000000000000363 